\title{
Evaluasi Konteks Program Pembinaan Prestasi Cabang Olahraga Hockey di Jawa Timur
}

\author{
Muhammad, Heryanto Nur \\ Prodi PJKR, Fakultas Ilmu Keolahragaan, Universitas Negeri Surabaya
}

*Corresponding author: doglo1974@gmail.com

\section{A R T I C LE INFO}

\section{Article history:}

Received 25 April 2018

Received in revised form $31 \mathrm{Mei}$

2018

Accepted 03 Juni 2018

Keywords:

Context evaluation, high

performance program, hockey

\begin{abstract}
A B S T R A C T
This study aims to analyze the context of long-term athlete development program in East Java hockey. The method used is the CIPP evaluation model. The research subjects are members of Hockey Indonesia in East Java Province. Data were collected using questionnaires and interviews. Data analysis techniques used descriptive qualitative. Evaluation results in policy-related contexts indicate that the subject of research receives national and local support. Also funding support is different from each other. Working closely with the university in terms of sport science and corporate to get sponsors is expected to improve the performance of research subjects in implementing high performance programs.
\end{abstract}

\section{Pendahuluan}

Hockey sebagai cabang olahraga saat ini mulai populer dan banyak dimainkan serta diakui keberadaannya di masyarakat. Hal ini dapat dilihat dari legalitas induk organisasi hockey yang telah diakui pemerintah dari tingkat lokal (daerah), nasional, regional hingga tingkat internasional. Oleh karena itu dalam berbagai kejuaraan multi-event, cabang olahraga hockey dipertandingkan. Dengan kondisi tersebut idealnya pembinaan prestasi di daerah pun semakin meningkat.

Prestasi cabang olahraga di Jawa Tmur pada kurun waktu 10 tahun ini tampak kurang menggembirakan. Dibuktikan dengan tidak adanya prestasi pada Pekan Olahraga Nasional (Pon) dari tahun 2004 hingga 2016. Dalam kurun waktu lebih dari 10 tahun, belum sekalipun tim Jawa Timur berhasil menjadi juara pada tingkat nasional. Oleh karena itu perlu dilakukan suatu evaluasi untuk menganalisa bagaimana hal tersebut bisa terjadi dan merumuskan suatu rekomendasi yang dapat diacu untuk memperbaiki kondisi yang ada. Evaluasi yang dilakukan dalam penelitian ini adalah evaluasi konteks terkait manajemen program pembinaan cabang olahraga hockey di Jawa Timur khususnya pada pengurus cabng (pengcab) anggota Federasi Hockey Indonesia Provinsi Jawa Timur.

Secara khusus penelitian ini akan menganalisa aspek konteks pada program pembinaan prestasi cabang olahraga hockey di Jawa Timur yang berkaitan dengan visi dan misi organisasi, dukungan dari pemegang kebijakan dan stake holder terkait, dan program kerja kepengurusan untuk mengetahui kelebihan dan kekurangan program pembinaan prestasi yang dilakukan dari sisi manajemen organisasi. Bagaimanapun juga organisasi yang baik dan sehat akan menjadi wahana yang memadai untuk menjalankan program pembinaan prestasi dengan baik. Dan organisasi yang bagus juga ditentukan oleh faktor 
kepemimpinan yang mumpuni yang tidak hanya mengelola sumber daya yang ada tapi juga menjadikan sumber daya tersebut menjadi lebih baik dan inovatif (Javier, Alfonso \& Louis, 2015).

\section{Metode Penelitian}

Metode yang digunakan dalam penelitian ini adalah dengan menggunakan model evaluasi CIPP yaitu evaluasi context, input, process, dan product. Namun dalam penelitian ini yang akan dianalisa adalah aspek konteks pada program pembinaan prestasi caban olahraga hockey di Jawa Timur. Penelitian ini dilakukan untuk menghasilkan rekomendasi terkait perbaikan manajemen organisasi (Stufflebeam, 2014).

Subjek penelitian dipilih secara purposif berdasarkan prestasi terbaik pengcab pada Pekan Olahraga Provinsi tahun 2015 di Banyuwangi yang terdiri atas pengurus cabang (pengcab) dari 5 daerah anggota Federasi Hockey Indonesia Provinsi Jawa Timur, yaitu Kota Surabaya, Kabupaten Sidoarjo, Kabupaten Gresik, Kabupaten Tulungagung, dan Kabupaten Banyuwangi. Subjek yang diambil adalah pengcab-pengcab yang memiliki prestasi dengan asumsi bahwa pengelolaan pengcab yang baik akan dapat menghasilkan produk pembinaan prestasi yang bagus, utamanya yaitu atlet yang muara akhir pembinaannya akan memperkuat tim Jawa Timur pada kejuaraan antar propinsi (event nasional).

Data dikumpulkan dengan menggunakan instrumen angket yang dikembangkan oleh peneliti dengan mengadop pada angket peneliti terdahulu tentang CIPP (Wiriawan, 2008) dan wawancara langsung dengan subjek penelitian yaitu ketua pengcab dan pelatih dari Kota Surabaya, Kabupaten Sidoarjo, Kabupaten Gresik, Kabupaten Tulungagung, dan Kabupaten Banyuwangi.
Kegiatan pengambilan data dilakukan dalam kurun waktu bulan Mei hingga Juni tahun 2017. Data yang terkumpul dianalisa secara deskriptif kualitatif dengan model alir sebagaimana yang dikembangkan oleh Miles \& Huberman dalam Sugiyono (2015) yang terdiri dari proses pengumpulan data, reduksi data, penyajian data, dan verifikasi serta penarikan kesimpulan.

\section{Hasil}

Dari data yang terkumpul menyebutkan bahwa seluruh ketua pengcab yang diwawancarai memiliki latar belakang ilmu keolahragaan dan memiiki pengalaman sebagai atlet, pelatih, dan official dalam cabang olahraga hockey yang mereka dapatkan sebelum menjadi pengurus. Adapun data terkait dukungan kebijakan yang mereka dapatkan dari lembaga dapat dilihat dari diagram yang disajikan berikut.

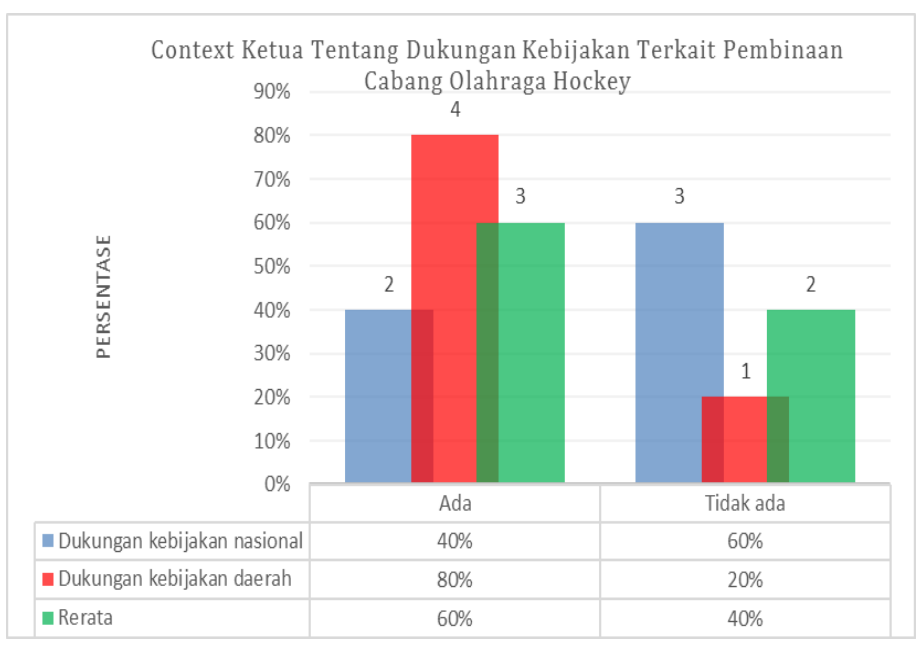

Diagram 1. Konteks Ketua tentang dukungan kebijakan terkait pembinaan cabang olahraga hockey

Dari diagram 1 dapat dilihat bahwa $40 \%$ pengcab mendapatkan dukungan kebijakan secara nasional dan $60 \%$ pengcab tidak. Sedangkan $80 \%$ pengcab mendapatkan 
dukungan kebijakan daerah dan $20 \%$ tidak. Dukungan kebijakan nasional meliputi dukungan terkait aturan dan petunjuk teknis program pembinaan prestasi. Dukungan kebijakan daerah yang pengcab dapatkan adalah dari KONI kota/kabupaten dan pemerintah kota/kabupaten (dispora) masingmasing yang berupa kebijakan pendanaan dan program pembinaan prestasi serta kebijakan program non prestasi. Di Kota Surabaya dan Kabupaten Sidoarjo terdapat program jalur prestasi untuk memberikan fasilitas kepada atlet usia sekolah untuk dapat melanjutkan pendidikan di skeolah negeri dengan prestasi minimal tingkat provinsi. Dukungan yang terbesar dari lembaga tersebut adalah pendanaan yang berkisar antara $25-80$ juta per tahun untuk menjalankan organisasi. FHI Kota Surabaya mendapatkan bantuan dana dari Dispora sebesar 50 juta per tahun. FHI Kabupaten Sidoarjo mendapatkan pendanaan dari KONI Sidoarjo sebesar 40 juta per tahun. FHI Kabupaten Gresik mendapatkan bantuan dana dari KONI Gresik sebesar 80 juta per tahun. FHI Kabupaten Tulungagung mendapatkan dana dari KONI setempat sebesar 25 juta per tahun, dan FHI Kabupaten Banyuwangi mendapatkan dana sebesar 36 juta per tahun.

Dukungan pendanaan ini digunakan untuk operasional organisasi dan pembinaan prestasi seperti pembelian alat tulis untuk kesekretariatan, pembelian perlengkapan latihan seperti stick, bola, perawatan lapangan, pelaksanaan program latihan, melakukan ujicoba try in dan try out, serta mengirim tim untuk mengikuti kejuaraan baik kejuaraan di tingkat lokal hingga keluar negeri. Beberapa daerah juga menggunakan dana yang didapatkan untuk memutar kompetisi internal, mengadakan penataran baik untuk pelatih dan wasit. Dana terrsebut juga digunakan untuk mengirim atlet mengikuti seleksi daerah sebagai persiapan mengikuti kejuaraan nasional (kejurnas).

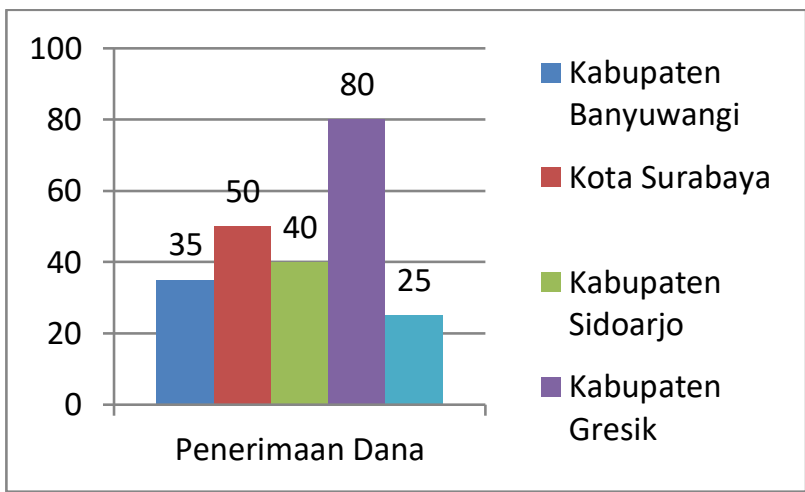

Diagram 2. Jumlah penerimaan dana masingmasing pengcab per tahun (dalam juta)

Sedangkan data untuk konteks pelatih pengcab disajikan sebagai berikut :

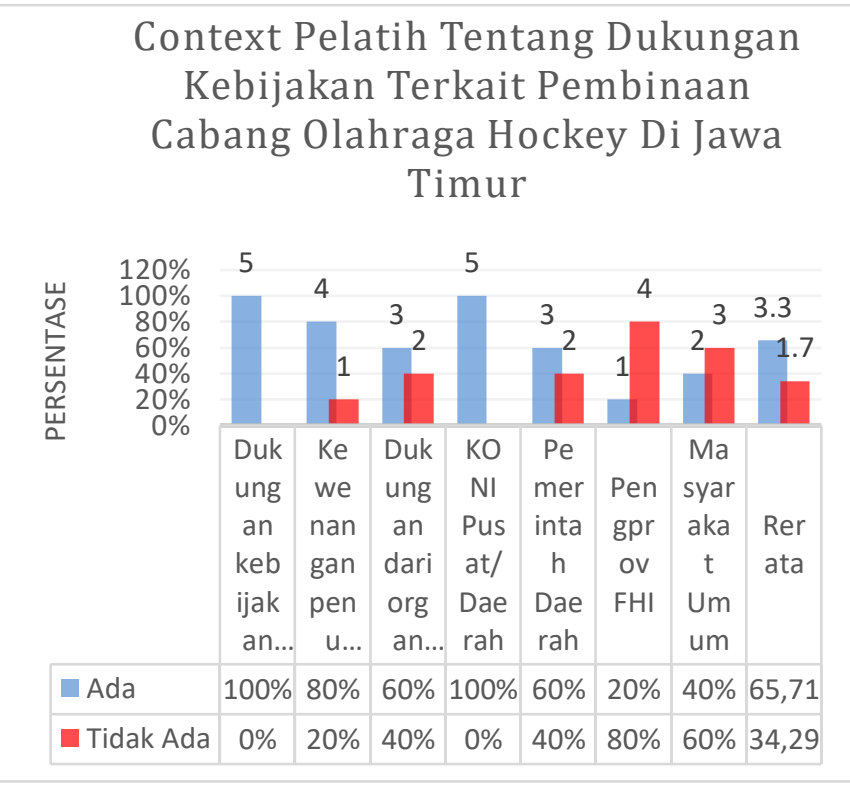

Diagram 3. Konteks pelatih tentang dukungan kebijakan

Data tersebut menunjukkan bahwa seluruh pelatih pengcab mendapatkan dukungan dari organisasinya di daerah, sebagian besar pelatih (80\%) diberikan kewenangan penuh mengembangkan program latihan untuk atlet. Pelatih juga mendaatkan dukungan dari organisasi di tingkat pusat sebesar $60 \%$ dengan bentuk mengikuti 
penataran pelatih. Seluruh pelatih mendapat dukungan dari KONI daerah masing-masing baik berupa pelatihan maupun pendanaan. Sedangkan dari pemerintah daerah/provinsi sebesar $60 \%$ khususnya pelatih yang pernah menjadi pelatih di tingkat provinsi. Dukungan dari pengprov sebesar $20 \%$, dan dukungan dari masyarakat umum $40 \%$ yang terdiri dari dukungan wali atlet pada saat proses latihan.

\section{Simpulan dan Rekomendasi}

Dari hasil penelitian yang dilakukan dapat disimpulkan sebagai berikut :

a. Ketua dan pengcab memiliki latar belakang ilmu keolahragaan. Hal ini menunjukkan bahwa ketua pengcab memiliki kompetensi yang bagus dalam memahami cabang olahraga yang dinaunginya. Hal ini sebenarnya memungkinkan untuk meningkatkan kemampuan mereka dalam hal ilmu keolahragaan agar dapat mengelola organisasi dan pelatihan atlet dengan lebih baik.

b. Ketua pengcab dan memiliki pengalaman baik sebagai pemain, pelatih, dan pengurus cabang olahraga hockey baik di organisasi di perguruan tinggi maupun di klub masing-masing sebelum menjadi pengurus di tingkat kota/kabupaten. Dengan demikian maka idealnya ketua dan pelatih pengcab dapat menjalankan program pembinaan prestasi dengan lebih baik kepada atlet.

c. Analisa konteks menunjukkan bahwa dukungan berupa kebijakan yang diterima oleh pengcab sebatas pada petunjuk teknis pembinaan prestasi dari lembaga nasional, dan dukunga berupa kebijakan terkait pengelolaan organisasi dan pendanaan hanya dari KONI dan dispora setempat. Hal ini membutuhkan terobosan dan inovasi mengingat dana yang diberikan tidak semuanya mencukupi untuk menjalankan program pembinaan prestasi.

Sedangkan saran yang dapat disampaikan dari kesimpulan tersebut adalah :

a. Pengcab harus membuat blueprint program pembinaan prestasi sesuai dengan kriteria yang lebih tinggi agar output prestasi atlet yang dihasilan dapat ditingkatkan dengan menyesuaikan dukungan kebijakan dan pendanaan yang diperoleh..

b. Pengcab perlu untuk mengadakan kerjasama dengan lembaga selain KONI dan dipsora setempat agar kebijakan dan pendanaanterkait program pembinaan prestasi dapat lebih ditingkatkan.

Rekomendasi yang dapat diberikan sehubungan dengan penelitian ini adalah sebagai berikut :

a. Ketua dan pelatih pengcab perlu mengadakan studi banding ke daerah atau negara lain yang lebih maju prestasi hockey agar dapat mengadopsi kebijakan yang diperoleh maupun pengelolaan pendanaan untuk program pembinaan prestasi yang dilakukan agar mendapatkan output berupa atlet yang memiliki performance tinggi.

b. Pengcab harus melakukan kerjasama baik dengan perguruan tinggi terkait penerapan sport science dan perusahaan guna mendapatkan sponsor untuk meningkatkan pendanaan sebagai upaya pengelolaan peningkatan program pembinaan prestasi.

\section{REFERENCES (Daftar Pustaka)}

Arikunto dan Safrudin (2010). Evaluasi program pendidikan pedoman teoritis praktis bagi mahasiswa dan praktisi. Jakarta : Bumi Aksara 
Muhammad, Heryanto Nur (2018) Evaluasi Program Pembinaan Prestasi Cabang Olahraga Hockey. Draft disertasi.

Imbroda-Ortiz, Javier, Alfonso, C. R., \& José Luis CM (2015). Sport Management, Leadership in The Organization. Journal of Physical Education and Sports Management.

Nurhasan (2006). Penilaian pembelajaran penjaskes. Jakarta : Pusat Penerbitan Universitas Terbuka.

Stufflebeam, Daniel L. And Coryn (2014). Evaluation theory, models, and aplications. San Fransisco : JossseyBass.

Sugiyono (2015). Metode penelitian manajemen. Bandung : Alfabeta.
UU (2005). Undang- Undang Republik Indonesia No. 3 Tahun 2005 tentang sistem keolahragaan nasional. Jakarta

Wiriawan, Oce (2008). Evaluasi kinerja pelatih dan pelatihan atlet di pusat pendidikan dan pelatihan bulutangkis di Jawa Timur. (disertasi yang tidak dipublikasikan), Universitas Negeri Surabaya. 